\begin{tabular}{|c|c|}
\hline Title & Finding a New Crystalline Sponge from a Crystal lographic Database \\
\hline Author(s) & Inokuma, Y asuhide; Matsumura, Kazuki; Y oshioka, Shota; Fujita, Makoto \\
\hline Citation & $\begin{array}{l}\text { Chemistry-an asian journal, 12(2), 208-211 } \\
\text { https://doi.org/10.1002/asia.201601551 }\end{array}$ \\
\hline Issue Date & 2017-01 \\
\hline Doc URL & http:/hdl.handle.net/2115/68137 \\
\hline Rights & $\begin{array}{l}\text { This is the peer reviewed version of the following article :Chemistry-an asian journal 12(2) Jan 17, } 2017 \text { pp.208-211, } \\
\text { which has been published in final form at http://onlinelibrary.wiley.com/doi/10.1002/asia.201601551/abstract. This } \\
\text { article may be used for non-commercial purposes in accordance with Wiley Terms and Conditions for Self-A rchiving }\end{array}$ \\
\hline Type & article (author version) \\
\hline File Information & manuscript.pdf \\
\hline
\end{tabular}

Instructions for use 


\section{Finding a New Crystalline Sponge from a Crystallographic Database}

\begin{abstract}
Empirical searching conditions were adopted to identify suitable candidates from the Cambridge Structural Database (CSD) for crystalline sponge hosts for X-ray crystallographic analysis of incoming guest compounds. After optimization of the solvent and soaking conditions, one of the candidates was used as a crystalline sponge for the structure determination of an aromatic guest.
\end{abstract}

Yasuhide Inokuma, ${ }^{*}$ Kazuki Matsumura, Shota Yoshioka, and Makoto Fujita*

Since the appearance of the crystalline sponge method, ${ }^{[1]}$ porous single crystals, including metal-organic frameworks, porous coordination polymers, and porous organic crystals, have received considerable attention as potential crystalline sponge hosts for the single crystal X-ray analysis of non-crystalline and trace amounts of compounds. ${ }^{[2]}$ However, only a limited number of porous crystals are known to serve as crystalline sponges, which can soak up and orient guest molecules inside their pores. ${ }^{[3]}$ Moreover, there is not yet a well-established strategy for the design and synthesis of new crystalline sponge hosts. Considering the increasing number of porous crystals deposited in the Cambridge Structural Database (CSD),${ }^{[4]}$ it would not be surprising for a potential candidate for target-oriented crystalline sponges to be found in this database. ${ }^{[5]}$ In this report, we demonstrate a semi-empirical database search to find new crystalline sponge candidates from the CSD. A new member of the crystalline sponge family was developed from these candidates by optimization of the solvent and guest uptake conditions.

For use as a crystalline sponge, the necessary features of a porous crystal are: (1) the pores are non-confined and large enough to accommodate target molecules from outside the crystal, and (2) guest exchange occurs in a single-crystal-tosingle-crystal fashion. From a practical point of view, recent research $^{[2]}$ suggests that the following additional features are also preferred: (3) low-symmetry space groups to avoid trapping of guest molecules across symmetry planes or rotation axes, (4) relatively low porosity to ensure the stability of crystals on guest soaking, and (5) a flexible, interpenetrated host framework that can induce effective host-guest interactions as observed in the prototype crystalline sponge $\left[\left(\mathrm{ZnI}_{2}\right)_{3}(\mathrm{tpt})_{2}\right]_{n} \quad(1 ;$ tpt $=\operatorname{tris}(4-$ pyridyl)triazine). ${ }^{[3 a]}$ Among the five conditions listed above, (1), (3), (4), and (5) can be input into the searching conditions using

[a] K. Matsumura, Dr. S. Yoshioka, Dr. Y. Inokuma. Prof. M. Fujita Department of Applied Chemistry, School of Engineering The University of Tokyo

7-3-1 Hongo, Bunkyo-ku, Tokyo, 113-8656 (Japan)

E-mail:mfujita@appchem.t.u-tokyo.ac.jp inokuma@eng.hokudai.ac.jp

[b] Dr. Y. Inokuma

JST PRESTO, 4-8-1 Honcho, Kawaguchi, Saitama, 332-0012 (Japan)

[ $\uparrow$ ] Current address: Division of Applied Chemistry, Faculty of Engineering

Hokkaido University

Kita 13, Nishi 8, Kita-ku, Sapporo, 060-8628 (Japan)

Supporting information for this article is given via a link at the end of the document.
ConQuest, ${ }^{[6]}$ whereas condition (2) must be satisfied by experimental optimization.

In this work, our goal was to find a new crystalline sponge host with a larger pore diameter $\left(>9.0 \times 9.0 \AA^{2}\right)$ than that of prototype sponge $1\left(8 \times 5 \AA^{2}\right)$. To satisfy initial conditions (1)(5), we adopted the following search criteria: (i) text search 'solvent' to find structures with solvent molecules or solventaccessible voids (condition 1), (ii) monoclinic or triclinic crystal systems with $Z \leq 4$ for low-symmetry structures (3), and (iii) text search 'catena' for interpenetrated structures (5). Because thousands of crystal structures met these conditions, we arbitrarily limited our search to (iv) porous $\mathrm{Cu}$ complexes composed of $\mathrm{H}, \mathrm{C}, \mathrm{N}, \mathrm{O}$, and Cu elements reported from 2010 to 2016 with $R_{1} \leq 0.10$ to give a reasonable number of candidates (189 hits) (Figure 1).

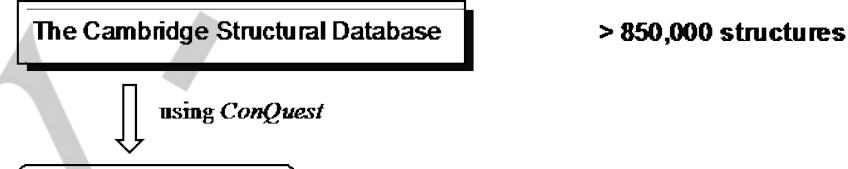

(i) text search 'solvent

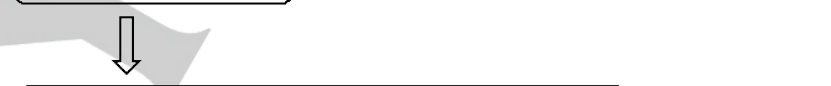

(ii) crystal system 'triclinic' or ' monoclinic' with ' $Z \leq 4^{\prime}$

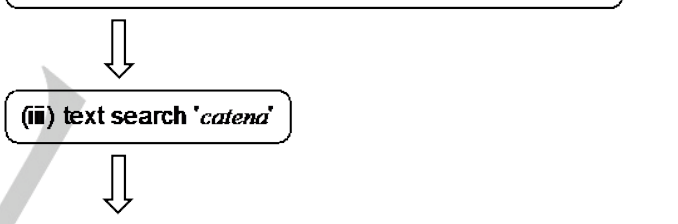

(iv) (arbitrary restrictions to limit the number of candidates)

Elements ' $\mathrm{C}, \mathrm{H}, \mathrm{N}, \mathrm{O}, \mathrm{Cu}$ '

Publication year'2010-2016

$\mathrm{R}$ factor ${ }^{\circ}<=0 . I^{*}$

$\prod$ using Mercury $\operatorname{Cs} D$

(v) non-confined voids

93 hits

$\prod$

(vi) Void volume $\leq 40 \%$ of the unit cel

59 hits

(vii) Narrowest pore cross-section $\geq 9 \times 9 \AA^{2}$

4 hits

Figure 1. Flowchart for the search for crystalline sponge candidates

The structures of the first candidates were visualized using Mercury CSD software ${ }^{[7]}$ to determine whether the interstitial voids were confined or non-confined, and to calculate the proportion of void space in the unit cell. When the first candidates were refined with three further conditions: (v) nonconfined voids, (vi) void volume $\leq 40 \%$ of the unit-cell volume calculated using a probe radius of $1.2 \AA$, and (vii) narrowest 
cross-section of the pore $\geq 9 \times 9 \AA^{2}$, four promising candidates ${ }^{[8]}$ were obtained [see the Supporting Information (SI)].

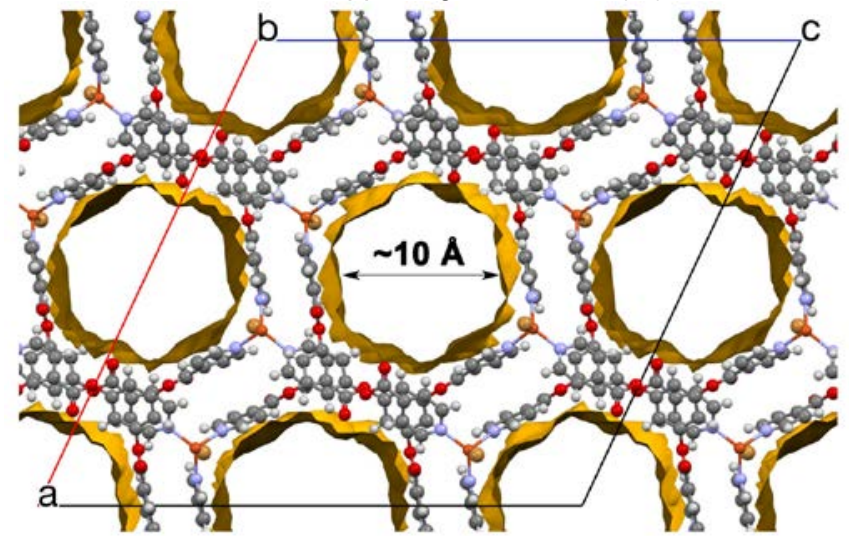

Figure 2. Network structure and pores of the crystalline sponge candidate $[\mathrm{CuBr}(\mathrm{btt})]_{\mathrm{n}}(2)$ viewed along the $b$ axis.

Considering the synthetic accessibility and feasibility, we selected coordination network $[\mathrm{CuBr}(\mathrm{btt})]_{n}(2$; btt $=$ benzene1,3,5-triyl triisonicotinate), reported by Yang and co-workers, ${ }^{[9]}$ as a crystalline sponge candidate to be studied for the optimization of the guest-soaking conditions (Figure 2). The interpenetrated framework of $\mathbf{2}$ contains one-dimensional cylindrical channels with a diameter of approximately $10 \AA$, which account for $40 \%$ of the unit cell volume (Figure 2). ${ }^{[10]}$ We first conducted a solvent tolerance test using common organic solvents (cyclohexane, toluene, chloroform, $\mathrm{CS}_{2}$, methanol, acetonitrile, and DMSO).



Figure 3. Microscope images of crystals of $\mathbf{2}$ soaked in test solvents at room temperature for $2 \mathrm{~d}$. Crystals soaked in methanol, acetonitrile, and DMSO were damaged on soaking.

Coordination network 2 was synthesized from the btt ligand and $\mathrm{CuBr}$ in chloroform/acetonitrile according to the reported procedure $^{[9]}$ to give red rod-like crystals. As-synthesized crystals of 2 were soaked in each test solvent at room temperature for 2 $\mathrm{d}$, and their crystallinity was checked using a microscope and Xray diffraction. The crystallinity was preserved for crystals soaked in cyclohexane, toluene, chloroform, and $\mathrm{CS}_{2}$, whereas those in methanol, acetonitrile, and DMSO were partially cracked after soaking and poorly diffracted X-rays (see the SI). For the former solvents, elemental analysis and extraction experiments using ${ }^{1} \mathrm{H}$ NMR spectroscopy indicated that the pore contents were almost completely replaced with the contacting solvent after soaking for $2 \mathrm{~d}$. Thus, we next examined guest uptake using these solvents.

To demonstrate crystalline sponge analysis with host $\mathbf{2}$, we selected 1-acetonaphthone (3), a liquid at room temperature, as a target guest because of its size and functional groups (aromatic $\pi$-plane, hydrogen-bond donor and acceptor). Because pore-embedded solvent molecules can sometimes block guest inclusion, ${ }^{[1 \mathrm{~b}]}$ we first conducted a contacting test to narrow down the most suitable solvent prior to the crystalline sponge analysis. Solvent-exchanged crystals 2 (ca. $1 \mathrm{mg}$ ) were directly contacted with guest $3(50 \mu \mathrm{L})$ under neat conditions. The crystals were separated by filtration after $3 \mathrm{~d}$, washed with the solvent originally contained in the crystals, and then digested by addition of ethylenediaminetetraacetic acid (EDTA). The ligand/guest ratios were then determined using ${ }^{1} \mathrm{H}$ NMR spectroscopy to be 1:0.92, 1:1.02, 1:1.80, and 1:0.94 for chloroform, cyclohexane, $\mathrm{CS}_{2}$, and toluene, respectively. This result indicates that guest exchange from $\mathrm{CS}_{2}$ to 1 acetonaphthone (3) is the most efficient among the four solvents that were compatible with the crystal.

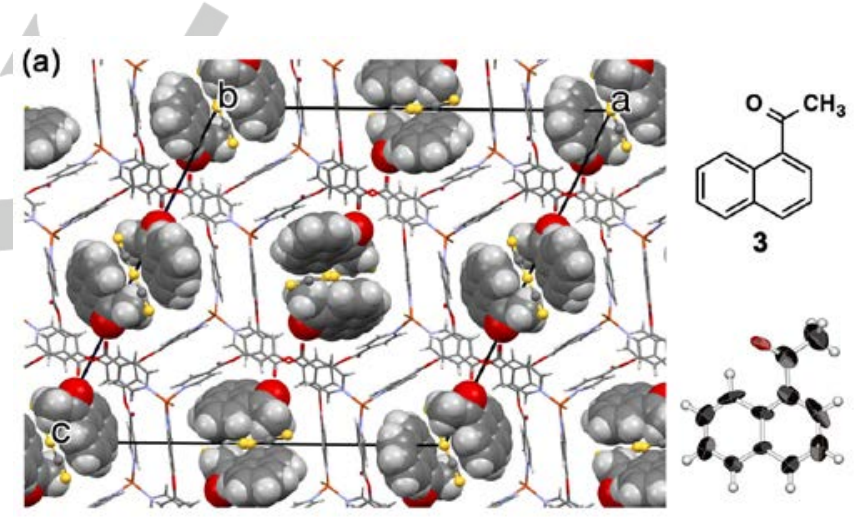

(b)

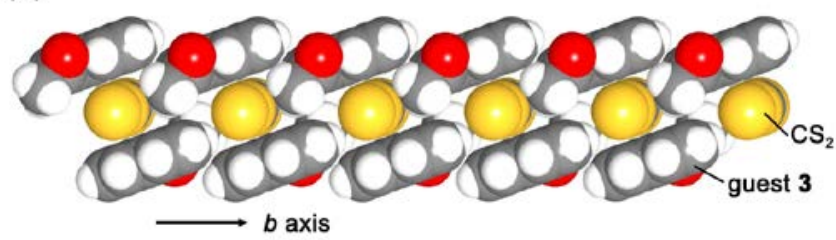

Figure 4. (a) Crystal structure of inclusion complex $\mathbf{3 \cdot 2}$ (left: packing structure viewed along the $b$ axis; guest $\mathbf{3}$, solvent $\mathrm{CS}_{2}$, and host $\mathbf{2}$ are drawn as CPK, ball-and-stick, and stick models, respectively; right: ORTEP drawing of guest 3 with $50 \%$ thermal ellipsoids). (b) Double-line arrangement of guests 3 with $\mathrm{CS}_{2}$ molecules inside the 1D channel of host 2.

After examination of several soaking conditions, a highquality inclusion crystal of $\mathbf{2 \cdot 3}$ was prepared by soaking a tiny $\mathrm{CS}_{2}$-exchanged crystal of $2\left(0.20 \times 0.14 \times 0.09 \mathrm{~mm}^{3}\right)$ in a $2.2 \mathrm{M}$ solution of guest 3 in $\mathrm{CS}_{2}(40 \mu \mathrm{L})$ over $3 \mathrm{~d}$ at room temperature. Single crystal X-ray analysis clearly showed that molecules of guest 3 were trapped in the 1D channel of host 2 (Figure 4), forming two columns along the $b$-axis. ${ }^{[1]}$ Although the space group changed from $P 2 / n$ (reported by Yang et al. ${ }^{[0]}$ to $P 2_{1} / C$ upon guest inclusion, the network structure of host 2 was essentially the same as its as-synthesized form. The carbonyl group of guest $\mathbf{3}$ was doubly hydrogen-bonded by two $\mathrm{C}_{\text {arom }}-\mathrm{H}$ 
protons of host $\mathbf{2}$, which resulted in a slightly non-planar conformation of $\mathbf{3}$ (the dihedral angles between the aromatic ring and the acetyl group were $30.7(4)^{\circ}$ and $38.8(4)^{\circ}$ for the two crystallographically inequivalent molecules of guest 3 ).

Importantly, the solvent $\mathrm{CS}_{2}$ molecules play a crucial role in filling the void space between the channel wall and the guest columns. Presumably, such tight packing in the channel is necessary to achieve high uptake and appropriate orientation of the guests. In fact, when we analyzed an inclusion crystal of $\mathbf{2 \cdot 3}$ prepared from cyclohexane solution, structural determination was unsuccessful owing to the serious disorder of the guests and solvents.

In summary, our results strongly indicate that there are a large number of crystalline sponge candidates in the CSD that could be used to analyze the structures of compounds of interest Although hundreds of candidates can be found quickly by adopting semi-empirical searching conditions based on the size of the target compound, the as-synthesized porous crystals do not always behave as good hosts without optimization of the soaking conditions. Therefore, pre-optimization of solvents and guest-soaking conditions are of great importance for successful structure analysis. We believe that our database search strategy will expand the repertoire of crystalline sponge hosts, and thus extend the scope of structural analysis available using the crystalline sponge method.

\section{Experimental Section}

\section{Solvent exchange of host crystals of 2 with $\mathrm{CS}_{2}$}

Host crystals of $\mathbf{2}$ were synthesized in test tubes on a $20-\mathrm{mg}$ scale in chloroform/acetonitrile according to the reported procedure. ${ }^{[9]}$ After the mother liquor was removed by decantation, the crystals were washed by addition and decantation of $\mathrm{CS}_{2}(5 \times 5 \mathrm{~mL})$. The crystals were then soaked in fresh $\mathrm{CS}_{2}(10 \mathrm{~mL})$ in a test tube for $2 \mathrm{~d}$ at room temperature. For X-ray diffraction analysis, crystals of $\mathbf{2}$ were kept in $\mathrm{CS}_{2}$ solvent until they were mounted onto the $\mathrm{X}$-ray diffractometer. For elemental and IR analyses, the crystals were filtered and air-dried on a funnel for $10 \mathrm{~min}$ before use.

Microscopic IR (single crystal, mineral oil): $\tilde{\mathrm{v}}=2924,2853,2361,2158$ (CS $)$ 1736, 1601, 1489, 1458, 1248, 1204, 1169, 1138, 1055, 1012, 964 , 874, 845, and $824 \mathrm{~cm}^{-1}$. Elemental analysis: calcd (\%) for $\left[\mathrm{CuBr}\left(\mathrm{C}_{24} \mathrm{H}_{15} \mathrm{~N}_{3} \mathrm{O}_{6}\right) \cdot 2.8\left(\mathrm{CS}_{2}\right)\right]_{n}: \mathrm{C} 40.34, \mathrm{H}$ 1.89, N 5.27; found: C 40.40 , H 2.07, N 5.37.

\section{Crystalline sponge analysis of 1-acetonaphthone 3}

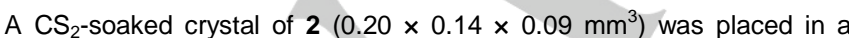
microvial ${ }^{[1 \mathrm{~b}]}$ with $30 \mu \mathrm{L}$ of $\mathrm{CS}_{2}$ using a micropipette. After addition of 1acetonaphthone (3) $(10 \mu \mathrm{L})$, the vial was sealed with a screw cap. The cap was pierced with a needle (hole diameter: $0.80 \mathrm{~mm}$ ), and the vial was allowed to stand at room temperature for $3 \mathrm{~d}$. The resulting crystal was then taken from the vial using a cryoloop and cryoprotectant (paratone oil) and subjected to single crystal X-ray and microscopic IR analyses.

Microscopic IR of inclusion crystal $\mathbf{2 \cdot 3}$ (single crystal, mineral oil): $\tilde{\mathbf{v}}=$ 2925, 2864, 2359, $2164\left(\mathrm{CS}_{2}\right), 2104,1748,1671$ (C=O in guest 3), 1602, $1506,1461,1377,1315,1233,1199,1168,1138,1053,1013,966,875$, and $847 \mathrm{~cm}^{-1}$.

\section{Acknowledgements}

This research was carried out as a part of the JST-PRESTO project, for which Y.I. is the principle investigator.

\section{Keywords: Porous Materials • Host-Guest Chemistry •} Crystallography $\bullet$ Database Search

[1] a) Y. Inokuma, S. Yoshioka, J. Ariyoshi, T. Arai, Y. Hitora, K. Takada, S. Matsunaga, K. Rissanen, M. Fujita, Nature 2013, 495, 461-466 Corrigendum: Nature 2013, 501, 262-262; b) Y. Inokuma, S. Yoshioka, J. Ariyoshi, T. Arai, M. Fujita, Nat. Protoc. 2014, 9, 246-252; c) M Hoshino, A. Khutia, H. Xing, Y. Inokuma, M. Fujita, IUCrJ 2016, 7 , 3910-3913.

[2] a) D. Kamimura, D. Urabe, M. Nagatomo, M. Inoue, Org. Lett., 2013, 15 5122-5125; b) E. V. Vinogradova, P. Müller, S. L. Buchwald, Angew. Chem. Int. Ed., 2014, 126, 3189-3192; c) A. G. O'Brien, A. Maruyama, Y. Inokuma, M. Fujita, P. S. Baran, D. G. Blackmond, Angew. Chem. Int Ed., 2014, 53, 11868-11871; d) N. Zigon, M. Hoshino, S. Yoshioka, Y. Inokuma, M. Fujita, Angew. Chem. Int. Ed., 2015, 54, 9033-9037; e) S. Yoshioka, Y. Inokuma, M. Hoshino, T. Sato, M. Fujita, Chem. Sci., 2015, 6, 3765-3768; f) S. Takizawa, K. Kishi, Y. Yoshida, S. Mader, F. Arteaga, S. Lee, M. Hoshino, M. Rueping, M. Fujita, H. Sasai, Angew. Chem. Int. Ed., 2015, 54, 15511-15515; g) S. Urban, R. Brkljača, M. Hoshino, S. Lee, M. Fujita, Angew. Chem. Int. Ed., 2016, 128, 27282732; h) Y. Inokuma, T. Ukegawa, M. Hoshino, M. Fujita, Chem. Sci. 2016, 7, 3910-3913; i) S. Yoshioka, Y. Inokuma, V. Duplan, R. Dubey, M. Fujita, J. Am. Chem. Soc., 2016, 138, 10140-10142; j) W. M. Bloch, N. R. Champness, C. J. Doonan, Angew. Chem. Int. Ed. 2015, 54 12860-12867.

[3] a) K. Biradha, M. Fujita, Angew. Chem. Int. Ed., 2002, 41, 3392-3395 b) S. Tashiro, R. Kubota, M. Shionoya, J. Am. Chem. Soc. 2012, 134 2461-2464; c) T. R. Ramadhar, S. Zheng, Y. Chen, J. Clardy, Chem Commun. 2015, 51, 11252-11255; d) E. Sanna, E. C. Escudero-Adán A. Bauzá, P. Ballester, A. Frontera, C. Rotger, A. Costa, Chem. Sci. 2015, 6, 5466-5472; e) G.-H. Ning, K. Matsumura, Y. Inokuma, M. Fujita, Chem. Commun. 2016, 52, 7013-7015

[4] C. R. Groom, I. J. Bruno, M. P. Lightfoot and S. C. Ward, Acta Cryst 2016, B72, 171-179

[5] Computational identification of porous crystals from CSD: a) Y. G. Chung, J. Camp, M. Haranczyk, B. J. Sikora, W. Bury, V. Krungleviciute, T. Yildirim, O. K. Farha, D. S. Sholl, R. Q. Snurr, Chem. Mater. 2014, 26, 6185-6192; b) J. D. Evans, D. M. Huang, M. Haranczyk, A. W Thornton, C. J. Sumby, C. J. Doonan, CrystEngComm 2016, 18, 4133 4141; c) K. J. Msayib, D. Book, P. M. Budd, N. Chaukura, K. D. M Harris, M. Helliwell, S. Tedds, A. Walton, J. E. Warren, M. Xu, N. B McKeown, Angew. Chem. Int. Ed. 2009, 121, 3323-3327.

[6] I. J. Bruno, J. C. Cole, P. R. Edgington, M. Kessler, C. F. Macrae, P. McCabe, J. Pearson and R. Taylor, Acta Cryst., 2002, B58, 389-397.

[7] C. F. Macrae, I. J. Bruno, J. A. Chisholm, P. R. Edgington, P. McCabe, E. Pidcock, L. Rodriguez-Monge, R. Taylor, J. van de Streek and P. A. Wood, J. Appl. Cryst., 2008, 41, 466-470.

[8] The identifier of the final 4 candidates on CSD are AKAYIV (ref. 9), IDUYOX (ref. 8a), MOXBOS (ref. 8b), and XEWDUA (ref. 8c): a) Z Zhang, L. Wojtas, M. Eddaoudi, M. Zaworotko, J. Am. Chem. Soc. 2013, 135, 5982-5985; b) N. Hermer, N. Stock, Dalton Trans. 2015, 44, 3720; c) X.-D. Zhu, Z.-J. Lin, T.-F. Liu, B. Xu, R. Cao, Cryst. Growth. Des. 2012, 12, 4708-4711.

[9] R. Yang, L. Li, Y. Xiong, J.-R. Li, H. C. Zhou, C.-Y. Su Chem. Asian J. 2010, 5, 2358-2368.

[10] The pores of 2 was visualized using Mercury CSD program with probe radius of $1.2 \AA$. In reference [9], the size of the effective channels and potential solvent-accessible voids (by PLATON) have been calculated to be $10 \times 10 \AA^{2}$ and $40 \%$, respectively.

[11] Crystallographic data for inclusion complex $\mathbf{2 \cdot 3}$ : $\left[\left(\mathrm{C}_{24} \mathrm{H}_{15} \mathrm{~N}_{3} \mathrm{O}_{6}\right)_{2}(\mathrm{CuBr})_{2}\right] \cdot 1.795\left(\mathrm{C}_{12} \mathrm{H}_{10} \mathrm{O}\right) \cdot 1.147\left(\mathrm{CS}_{2}\right), \quad M=1562.53$ 
crystal size: $0.20 \times 0.14 \times 0.09 \mathrm{~mm}^{3}$, Monoclinic, space group $P 2_{1} / \mathrm{c}$, $=32.249(6) \AA, b=7.770(2) \AA, c=30.641(6) \AA, \beta=116.03(3)^{\circ}, V=$ 6899(3) $\AA^{3}, Z=4, D_{c}=1.504 \mathrm{~g} / \mathrm{cm}^{3}, T=93(2) \mathrm{K}, 2.108^{\circ}<\theta<27.291^{\circ}$ 13152 unique reflections out of 35147 with $I>2 \sigma(I), \mathrm{GoF}=1.066$, final
$R$ factors $R_{1}=0.0529$, and $w R_{2}=0.1818$ for all data. CCDC 1511768 contains the supplementary crystallographic data. 


\section{Entry for the Table of Contents}

\section{COMMUNICATION}

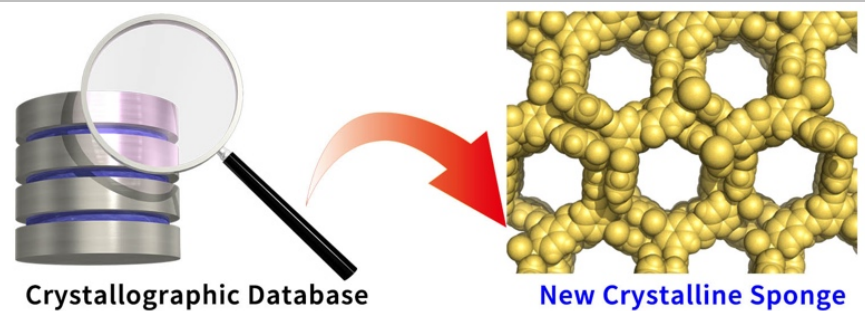

Yasuhide Inokuma, * Kazuki Matsumura, Shota Yoshioka, and Makoto Fujita*

Page No. - Page No.

Finding a New Crystalline Sponge from a Crystallographic Database

Promising candidates for new crystalline sponges for analysis of the structures of non-crystalline compounds by X-ray diffraction were selected from a crystallographic database using semi-empirical searching conditions. After optimization of the guest-soaking conditions, a new crystalline sponge with large one-dimensional channels was discovered.

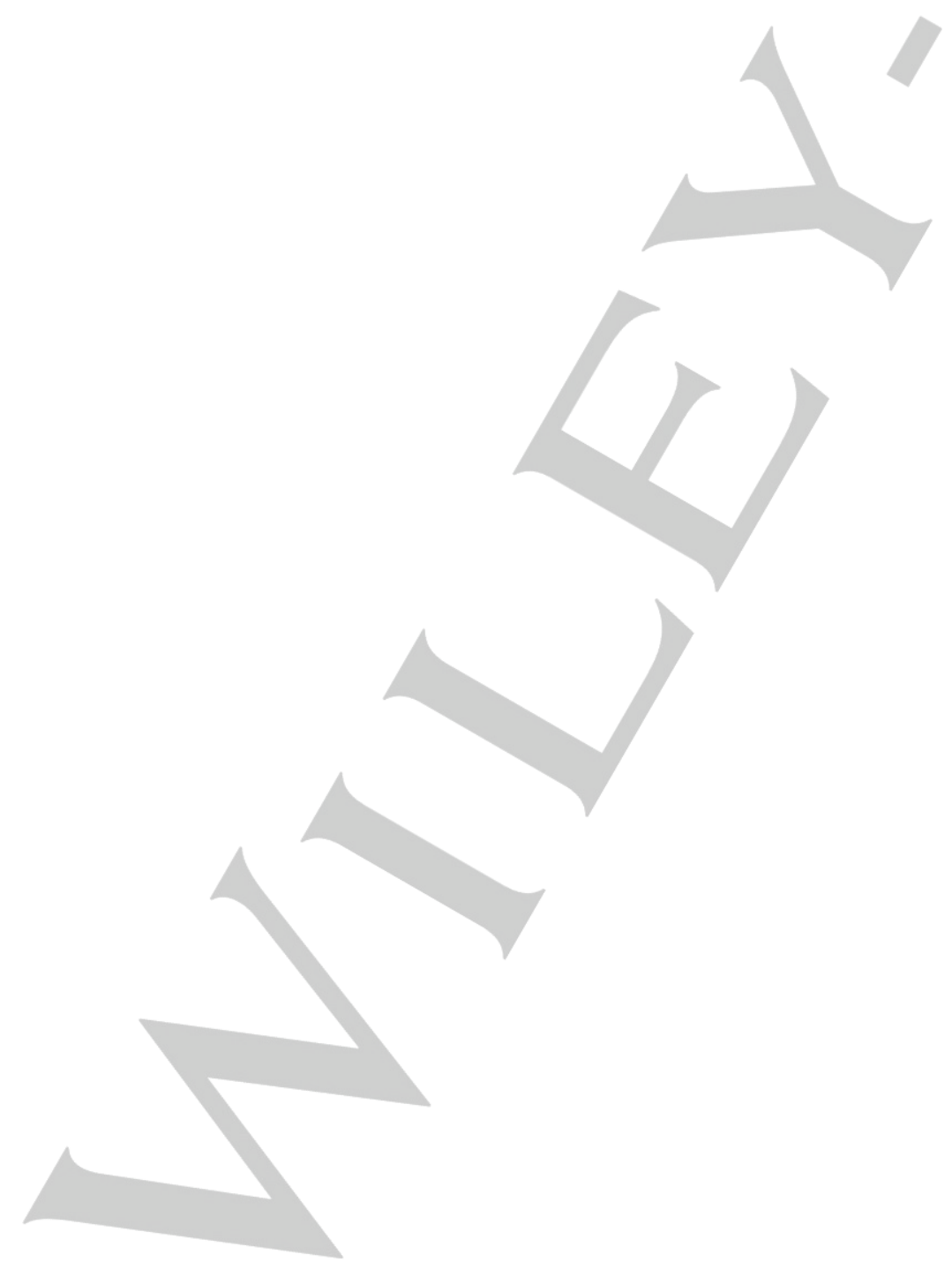

